\title{
O aborto e o uso do corpo feminino na política: a campanha presidencial brasileira em 2010 e seus desdobramentos atuais*
}

\author{
Tânia Mara Campos de Almeida** \\ Lourdes Maria Bandeira*"
}

\section{Resumo}

O tema do aborto ocupou o segundo turno da última eleição presidencial no Brasil, que teve pela primeira vez uma candidata mulher. A partir dos discursos públicos, analisam-se as pressões sofridas pela e pelo candidata/o em enfrentar a descriminalização do aborto, os argumentos religiosos contra o aborto em um Estado laico, o tratamento dos grupos religiosos dado ao corpo das mulheres, sendo esse um de seus redutos de controle, e o embate entre a visão da sexualidade feminina como um "território" de manipulação política e a perspectiva dos direitos sexuais e reprodutivos.

Palavras-chave: Aborto, Política, Religiosidade, Direitos Sexuais e Reprodutivos.

\footnotetext{
* Recebido para publicação em 28 de fevereiro de 2012, aceito em 6 de fevereiro de 2013.

** Professora Adjunta do Departamento de Sociologia, Universidade de Brasília (UnB).taniamaraunb@gmail.com e taniamaraca@unb.br

**** Professora Titular do Departamento de Sociologia, Universidade de Brasília (UnB). lourdesmbandeira@yahoo.com.br
}

cadernos pagu (41), julho-dezembro de 2013:371-403. 
O aborto e o uso do corpo feminino na política

Abortion and the Use of the Female Body in Politics: the Brazilian Presidential Campaign in 2010 and Its Current Developments

\begin{abstract}
The abortion issue has been in the center of discussions in the second round of the last presidential election in Brazil, which had for the first time a female candidate. The analyzes of the public discourses given during the campaign demonstrates the pressures suffered by the candidates when facing the decriminalization of abortion: religious arguments against abortion in a secular state; the treatment religious groups give to women's bodies; and the clash between the vision of female sexuality as a "territory" of political manipulation and as a prospect of sexual and reproductive rights.
\end{abstract}

Key Words: Abortion, Politic, Religiosity, Sexual and Reproductive Rights. 
O tema do aborto ocupou a cena política na última eleição presidencial no Brasil e foi especialmente intensificado no segundo turno, em outubro de 2010. Esse período trouxe, como fato inédito, a presença de uma candidata mulher em confronto com um político experiente em pleitos legislativos e executivos. Como tal tema não emerge em um campo pacificado na nossa sociedade, durante os embates iniciais, a e o candidata/o evidenciaram posições ambíguas a seu respeito, mas terminaram a disputa combatendo o aborto como opção pessoal.

Provavelmente a/o candidata/o não desconheciam e não desconsideraram a importância do conjunto de forças antagônicas que se manifestaram durante a campanha a propósito do tema do aborto. Em meio à polarização entre as organizações religiosas mais radicais, a exemplo dos grupos católicos Pró-Vida e Opus Dei, e a militância feminista, que se pôs veementemente contra a intervenção religiosa na cena política, a/o candidata/o tinham noção da pressão que sofriam em busca de se politizar as questões afeitas à sexualidade e à reprodução das mulheres (Rocha \& Barbosa, 2009). Contudo, observa-se que as situações que envolviam o "aborto legal" e os agravos à saúde das mulheres em decorrência da clandestinidade do aborto foram lembrados apenas pelas feministas (Barsted, 2009).

A candidata, hoje presidenta do Brasil, Dilma Rousseff, não contava com trajetória em cargos eletivos, embora tivesse ocupado postos importantes nos executivos estadual e nacional, como o de ministra de Minas e Energia (2002-2005) e da Casa Civil da Presidencia da República (2005-2010) nos governos de Luís Inácio Lula da Silva (mandatos 2002-2005 e 2006-2010). Como ministra da Casa Civil, ganhou popularidade e tornou-se a candidata governista pelo Partido dos Trabalhadores (PT). Sua história de militância política - participação em grupos guerrilheiros contrários à ditadura militar nos anos 1960 e 1970 e sua prisão - sempre foi bastante midiatizada, assim como o fato de apresentar-se desvinculada de qualquer prática religiosa. 
O aborto e o uso do corpo feminino na política

Em oposição, encontrava-se José Serra, autodeclarado católico e pertencente ao Partido da Social Democracia Brasileira (PSDB). Ocupou cargos de relevância nacional: deputado federal constituinte (1987-1991), deputado federal (1991-1995), senador (1995-2003), prefeito de São Paulo (2005-2006), ministro do Planejamento e Orçamento (1995-1996), ministro da Saúde (19982001) e govenador do estado de São Paulo (2006-2010), tendo sido o primeiro governador eleito em um único turno. Nas duas vezes em que se candidatou à presidencia, foi derrotado no segundo turno (em 2002 e 2006).

A análise ora proposta busca compreender, a partir da movimentação e dos discursos públicos dessas candidaturas, enunciados pela mídia nacional e seus programas eleitorais, o jogo de retórica política em torno das seguintes questões:

- Quais as pressões desencadeadoras da hesitação da e do candidata/o em enfrentar a descriminalização do aborto e em posicionarem-se frente ao debate? Em que medida essa hesitação se deve ao conservadorismo não apenas da sociedade, mas da/o própria/o candidata/o?

- Quais os argumentos centrais dos segmentos religiosos contra a descriminalização do aborto e como influenciaram a e o candidata/o, considerando que o Estado se define como laico?

. Como as/os religiosas/os se mobilizaram usando o corpo e a sexualidade feminina como seus objetos? Seriam, esses, redutos privilegiados do exercício de controle das igrejas cristãs na contemporaneidade?

. Como a sexualidade feminina ainda se constitui em um território de manipulação política, mesmo diante de uma candidata mulher ao mais alto cargo do executivo brasileiro e que se manifestou pela descriminalização do aborto em 2007? Quais as implicações desse período eleitoral hoje, em particular no que se refere à garantia dos direitos sexuais e reprodutivos das mulheres?

Cabe ressaltar que o posicionamento desfavorável à despenalização do aborto por parte da sociedade brasileira, embora seja mobilizada em termos religiosos, possui um substrato 
social bem mais amplo que a simples lealdade dos/as devotos/as às ideias de suas lideranças religiosas. Em trabalhos futuros, será importante desenvolver reflexões sobre a profundidade dos valores $e$ das representações sociais envolvidos nas práticas individuais, uma vez que não necessariamente elas se coadunam com as expressões políticas coletivas.

Escassas são as pesquisas, no Brasil como na América Latina, sobre o aborto em si e o uso de sua problemática nas campanhas eleitorais. Deve-se investigar contextos sociopolíticos e religiosos bastante complexos, que envolvem uma discussão aprofundada muito além do status jurídico que tem o aborto em cada país latino.

\section{Aborto e sociedade brasileira: conservadorismo e contradições}

A legislação brasileira sobre o aborto, datada de 1940, permite sua prática em apenas duas situações, inclusive na rede pública de saúde: em caso de risco da vida da gestante ou se a gestação resulta de violência sexual (estupro ou incesto), conforme o Artigo 128, I e II, do Código Penal. Fora esses casos, a prática do aborto e o auxílio a ela são crimes. Reconhecê-los judicialmente não é simples, pois é comum que a aplicação de risco para a vida se reduza a situações extremas em que a mulher se encontra em alto risco de morte (González, 2009), bem como a comprovação do estupro demanda procedimentos difíceis de serem efetivados rapidamente.

$\mathrm{O}$ aborto previsto em lei passou a ser re-significado como aborto legal, resultado da atuação do movimento feminista e de importantes parceiras/os do campo da saúde. Começou a ser atendido de modo regular em alguns hospitais públicos, em um país que se redemocratizava a partir da segunda metade dos anos 1980 (Rocha \& Barbosa, 2009).

No entanto, na América Latina e no Caribe vem se firmando um conjunto de documentos e plataformas, tanto em âmbito 
O aborto e o uso do corpo feminino na política

internacional como regional, que contém medidas orientadas à realização dos direitos humanos das mulheres e à proteção de sua saúde, vida e dignidade, o que aponta para a necessidade de políticas públicas na área do planejamento familiar e do combate à violência contra a mulher. Dentre estes estão a Convenção para a Eliminação da Discriminação contra a Mulher (CEDAW), a Convenção contra a Tortura e as Conferências Internacionais de Viena (1993), Cairo (1994) Beijing (1995) e Nova York (2000). Além disso, as Nações Unidas tem feito recomendações sobre o direito de toda pessoa ao desfrute de boa saúde física e mental, o que contribui à configuração de padrões norteadores em relação ao aborto. Nesse sentido, a Comissão Econômica para a América Latina e o Caribe (CEPAL) vem atuando para garantir a prática do aborto seguro, o que inclui sua despenalização, o acesso a causas permitidas (quando estipuladas pela lei de cada nação) $e$ estratégias dirigidas à redução do dano.

$\mathrm{Na} 11^{\mathrm{a}}$ Conferência Regional sobre a Mulher da América Latina e Caribe realizada no Brasil, em 2010, os governos participantes assinaram o Consenso de Brasília, que assume a promoção da autonomia das mulheres e a igualdade de gênero, "considerando que la salud integral de las mujeres depende de medidas concretas para reduzir a morbimortalidad materna y el embarazo adolescente y asegurar una mejor calidad de vida (...)". Acordaram ações para

promover la salud integral y los derechos sexuales $y$ reproductivos de las mujeres, específicamente revisar las leyes que prevén medidas punitivas contra las mujeres que se hayan sometido a abortos (...) y garantizar la realización del aborto en condiciones seguras en los casos autorizados por la ley (Vélez, 2011:05).

Embora o Brasil participe e reitere os compromissos internacionais na área dos direitos humanos das mulheres, paradoxalmente, mantém uma legislação restritiva e punitiva que 
criminaliza o aborto. Conforme Mastrella (2011), isso não impede que tal prática seja feita por milhões de brasileiras. A Pesquisa Nacional sobre o Aborto indica que $15 \%$ das brasileiras, entre 18 e 39 anos, já cometeram pelo menos um aborto (Diniz e Medeiros, 2010). A gravidade do aborto para as mulheres não é, portanto, desconhecida no Brasil e o tema é gerador de polêmicas, uma vez que sua prática clandestina é estimada em torno de 600 mil casos por ano. Como são feitos, no geral, em condições precárias de saúde e higiene, têm-se consequências dramáticas. Cerca de 200 mil mulheres acabam tendo sequelas, sofrendo perfuração do útero ou infecção. Disso resulta uma elevada taxa de mortalidade, reforçando-o como sério problema de saúde pública (Ministério da Saúde, 2007; Rocha \& Barbosa, 2009).

Diversos interesses e concepções emergiram diante dessa realidade, impondo-se na arena das disputas políticas. Nas eleições de 2010, tornou-se ponto importante no debate presidencial no primeiro turno $e$ foi se intensificando ao seu término em 03 de outubro, haja vista que, no dia 28 de setembro, dia internacional de luta pela despenalização do aborto na América Latina e no Caribe, a discussão foi aquecida. A sociedade civil manifestou-se sob diferentes vozes a favor da descriminalização do aborto, a exemplo da Rede Feminista de Saúde que explicitou no documento $A$ saúde das mulheres merece seu voto, que a

saúde das mulheres e os direitos sexuais e reprodutivos são um tema político de primeira grandeza [...] com a participação das mulheres e de um estado laico sem influencia religiosa [...] porque este é um assunto a ser tratado nas eleições, a Rede busca com esta plataforma o diálogo político com candidatas e candidatos às eleições de 2010 (Rede Feminista de Saúde, 2010:01).

Esse documento, com 17 pontos, deu destaque para dois deles com trechos em negrito: 
O aborto e o uso do corpo feminino na política

Ponto 6 - Assumir o compromisso com o fim da legislação que criminaliza as mulheres pela realização de abortos voluntários e posicionar-se pela legalização a partir do respeito aos direitos humanos e porque os abortos inseguros são um grave problema de saúde pública.

Ponto 7 - Garantir às mulheres grávidas de fetos incompatíveis à vida extra-uterina a antecipação terapêutica do parto sem a autorização prévia da Justiça.

A questão do aborto mobilizou o movimento feminista, os partidos políticos e as frentes parlamentares. Esses agrupamentos, perpassados por identidades contrárias, compuseram um complexo jogo político no Congresso Nacional a partir de sua organização em grupos laicos em oposição a grupos religiosos: frente parlamentar de saúde e bancada feminina versus bancadas evangélica e católica. Autointitulados de congressistas "pró-vida", os parlamentares destas últimas vêm tentando obter legitimidade pública em seu discurso contra o aborto e outros temas polêmicos sobre a vida humana (células-tronco embrionárias, eutanásia, concepção, homossexualidades, dentre outros) fundamentandose, de modo geral, em uma moral que define a vida como um valor transcendente (Duarte, Natividade, Gomes e Menezes, 2009).

A despeito do debate histórico, aberto há mais de três décadas, sobre o aborto pelas feministas e pelos setores organizados mais arejados da nossa sociedade, a despenalização do aborto ainda faz parte de um conjunto de temas "considerados como um corpo estranho na cultura e na legislação(...)" (Barsted, 2009:08). O conservadorismo expresso nos dois turnos eleitorais indicou grande sintonia entre os/as parlamentares, representantes de movimentos religiosos, e segmentos da população, revelando a face moralista e patriarcal da sociedade, bem como certa "partidarização" das igrejas. Nas expressivas palavras de Heilborn (2011:32),

trata-se de uma imensa hipocrisia: aqueles que podem pagar um aborto em condições seguras $\mathrm{o}$ fazem 
tranquilamente; as clínicas não se omitem e chegam a contar com a proteção de policiais corrompidos.

O crescimento do conservadorismo mundial sobre esse tema, por uma perspectiva religiosa, tem levantado vários debates (Mujica, 2007), inclusive nas eleições de 2012 nos Estados Unidos. Estudos como, por exemplo, a revisão das disputas conceitual e política provocadoras de tensões no binômio aborto e religião nos campos da militância feminista, das religiões e de demais atores/atrizes, por Rosaldo-Nunes (2009) começam a ser elaborados. Em particular, essa face conservadora da sociedade brasileira já tinha se evidenciado em outros momentos, especialmente quando se tratava de se posicionar a respeito do aborto e do corpo feminino. Em maio de 2008, o projeto de lei 1135/91, encaminhado pelo governo do presidente Luis Inácio Lula da Silva (Lula) à Câmara dos Deputados que previa a extinção da criminalização do aborto, bem como a interrupção voluntária da gravidez até 12 semanas, foi rejeitado na Comissão de Seguridade Social e Família, como na de Cidadania e Justiça.

Em contraposição, em 19 de maio de 2010, foi aprovado pela mesma Comissão de Seguridade Social e Família o "Estatuto do Nascituro" (Projeto de Lei 478/2007), que visa proibir o aborto em qualquer hipótese, afastando os casos de aborto legal. Esse projeto, ainda em tramitação no Congresso Nacional, baseia-se na crença religiosa de que a vida tem início desde a concepção e que o óvulo e o espermatozóide, fecundados, já seriam portadores de direitos. Essa definição dificulta a futura legalização do aborto por decisão da mulher, coloca em risco as duas possibilidades legais hoje existentes e repercute negativamente em pesquisas com células-tronco de embriões.

O conservadorismo da sociedade brasileira encontrava-se inflado no ano eleitoral, como também expressaram os resultados de pesquisas a respeito do tema. Em março de 2007, o instituto de pesquisas Datafolha divulgou: $65 \%$ dos brasileiros pensam que a atual legislação sobre o aborto não deve ser alterada; $16 \%$ 
disseram que deveria ser expandida para permitir a prática para outras causas além das duas legalizadas; $10 \%$ que o aborto deveria ser descriminalizado e $5 \%$ declararam não ter posição sobre o assunto. A última enquete sobre a opinião da população foi realizada pelo instituto Vox Populi, em dezembro de 2010. O estudo revelou aumento da rejeição ao aborto: $82 \%$ dos brasileiros defenderam a manutenção da atual legislação, $14 \%$ concordaram com a sua descriminalização e $4 \%$ declararam-se indecisos.

No contexto eleitoral, o tema tornou-se um promissor campo de disputas para a e o candidata/o, ao mesmo tempo em que era cobrado dela/e posicionamento público em relação ao comprometimento com a despenalização, ou não, do aborto. Se em outras situações políticas suas considerações em relação ao tema podiam ser evasivas, no segundo turno da campanha lhes eram exigidas manifestações explícitas e inúmeras ratificações. $\mathrm{Na}$ verdade, o/a candidato/a se tornaram reféns da problemática do aborto, pois teriam elementos argumentativos para, inclusive, se contraporem à sua fixação como pauta central de suas campanhas. Essa forma de se posicionar a respeito acabou sendo um ponto de concordância entre ambos.

José Serra era internacionalmente conhecido por posições tidas como progressistas em questões afeitas à saúde pública e à humanização do aborto legal, quando Ministro da Saúde. Aliás, em suas ações ministeriais de enfrentamento à AIDS, várias ideias contrárias ao pensamento oficial do Vaticano foram aqui disseminadas e exportadas para outros países, assim como ideias a respeito da contracepção. Contudo, mostrou-se conservador sobre o aborto. Desde 2002, declarou não ser a favor da sua legalização, pois supunha que a prática seria desmedida. Passados oito anos, afirmou ser o aborto terrível e que, se liberado, o país se tornaria uma carnificina. Em 2010, proferiu discursos tradicionalistas e adotou comportamentos afinados com as alas retrógradas das igrejas cristãs. Percebeu, na junção entre religiosidade e controle da vida das mulheres, a oportunidade de reverter a segunda posição na tendência eleitoral. 
Conforme Mariano (2011), o candidato reuniu-se com arcebispos e o cardeal primaz do Brasil, bem como obteve apoio de lideranças evangélicas. Antes disso, Serra havia conquistado o apoio da Convenção Geral das Assembleias de Deus no Brasil, a maior agremiação assembleiana nacional. $\mathrm{O}$ último programa eleitoral do primeiro turno exibiu-o lendo a Bíblia para uma eleitora $e$ a primeira propaganda no segundo turno apresentou-o "temente a Deus", defensor dos 'valores da família' e dos 'valores cristãos', homem público que "sempre condenou o aborto", junto com a imagem de grávidas e com a promessa de "cuidar dos bebês antes que nasçam". De certa forma, manipulou uma retórica religiosa maniqueísta do bem contra o mal.

No entanto, uma situação inesperada atingiu sua campanha: sua esposa afirmou que a candidata Dilma era a favor de "matar criancinhas". Dias depois, a Folha de São Paulo, de 16 de outubro de 2012, publicou relato de uma de suas ex-alunas, contando que a mesma teria dito a uma turma que havia realizado aborto na juventude - depoimento confirmado por outra ex-aluna. Tanto essa declaração quanto panfletos retrógrados deram oportunidade a Dilma de desmenti-los. Daí em diante, Serra passou a defender-se de acusações de instrumentalizar politicamente valores morais e grupos religiosos, estimular um clima eleitoral inquisitorial e patrocinar calúnias contra a petista.

Por outro lado, Dilma havia declarado em 2007 e 2009, que era a favor da descriminalização do aborto. O PT também se posicionou favorável em 2007:

defesa da autodeterminação das mulheres, da descriminalização do aborto e regulamentação de todos os casos no serviço público, evitando assim a gravidez não desejada e a morte de centenas de mulheres, na sua maioria pobres e negras, em decorrência do aborto clandestino (Resoluções do $3^{\circ}$ Congresso do PT, 2007). 
O aborto e o uso do corpo feminino na política

Cabe lembrar que o governo Lula, enquanto Dilma estava na Casa Civil, foi o disparador do projeto de lei que visava sua despenalização. Mas, em julho de 2010 e em contexto eleitoral, a candidata e o Presidente Lula se disseram não defensores do aborto - apenas defensores estritos do cumprimento da lei. E, após o primeiro turno eleitoral, a candidata afirmou:

Eu não tenho o menor problema de tocar nas questões religiosas. Minhas propostas têm tudo a ver com todas as religiões do Brasil. Eu sou de uma família católica. Eu sempre fui a favor da vida. Eu tenho uma proposta de valores. Um princípio nosso de valorizar a vida em todas as suas dimensões (Revista Veja, 05/10/2010).

Conforme Mariano (2011), Dilma sofreu forte oposição de lideranças católicas e evangélicas, vistas como moral e politicamente conservadoras. Para reduzir a rejeição, deixou de apresentar-se ora agnóstica, ora acreditar em "uma força maior que a gente", ora cristã para assumir-se católica e estreitar relações com esses grupos. Por exemplo, em 2008, participou do acordo entre a Santa Sé e o Estado brasileiro e cumprimentou o Papa; em 2009, assistiu à missa num santuário, onde leu trecho da Bỉblia; e, reuniu-se com bispos do Conselho Permanente da Conferência Nacional dos Bispos do Brasil (CNBB). Em 2010, suas articulações e concessões religiosas ampliaram-se: ordenou à Secretaria de Promoção da Igualdade Racial o adiamento do Plano Nacional de Proteção à Liberdade Religiosa, que previa a legalização fundiária e o tombamento de imóveis ocupados por centros de umbanda e candomblé.

\section{Religião e a disputa política: Estado laico?}

Segundo Calado (2010), no Brasil, a laicidade teve início no ano de 1890 , com o Decreto $\mathrm{n}^{\circ} 119-\mathrm{a}$, sendo confirmada com a Constituição de 1891 e as demais. A atual, de 1988, apresenta o caráter laico do Estado brasileiro em seu artigo 19, I: 
É vedado à União, aos Estados, ao Distrito Federal e aos Municípios: I - estabelecer cultos religiosos ou igrejas subvencioná-los, embaraçar-lhes o funcionamento ou manter com eles ou seus representantes relações de dependência ou aliança, ressalvada, na forma da lei, a colaboração de interesse público (Constituição Federal, 1988).

Assim, separa-se a religião do poder público, não se permitindo a subvenção, a aliança ou a dependência, comum em Estados confessionais, com instituição religiosa.

No entanto, tal configuração só tem existido na teoria no Brasil, uma vez que as Igrejas interferem na legislação brasileira e nas práticas políticas do Executivo. A dita "partidarização" das Igrejas, particularmente em períodos eleitorais, evidencia a impossibilidade dos governantes e futuros governantes de um Estado (supostamente) laico atuar sem cair na censura prévia das opiniões religiosas e com elas ter que negociar. A intromissão das correntes religiosas cristãs manifesta-se com ênfase nos temas já mencionados, bem como na evidência de símbolos religiosos em repartições públicas. Vale ressaltar que faz parte do texto constitucional, no próprio artigo 19, inciso I, certa ambiguidade ao “... estabelecer, de forma genérica, que no caso de interesse público, havendo lei, os entes estatais podem colaborar com os cultos religiosos ou igrejas, bem como não pode embaraçar-lhes o funcionamento" (Pereira, 2011:s.p.). É, enfim, evidente a difícil dissociação entre Estado e Igreja(s), especialmente em contextos como o da América Latina, em que prevalece o ethos religioso extremamente forte juntamente com a presença política significativa das igrejas cristãs, em particular da Igreja Católica (Rosado-Nunes, 2009).

Mariano (2011) afirma que, desde o processo de redemocratização do país nos anos 1980, evangélicas/os, protestantes históricas/os e católicas/os foram assediadas/os por partidos e candidatas/os a participarem das eleições. Foi, porém, na eleição presidencial de 2010 que a influência e o poder de 
O aborto e o uso do corpo feminino na política

dirigentes, grupos e movimentos católicos e pentecostais sobre candidatas/os atingiram seu ápice. Conseguiram pressionar as campanhas, as estratégias $e$ as propostas eleitorais de Dilma e Serra. Conseguiram, sobretudo, que questões morais e religiosas tivessem destaque na competição eleitoral. Ágeis no campo político e no uso da mídia religiosa, das redes sociais e dos cultos religiosos, pressionaram o governo Lula a alterar o III Plano Nacional de Direitos Humanos (PNDH), lançado em 2009. Em nota da CNBB e documento assinado por 67 bispos, a Igreja Católica opôs-se a pontos do texto sobre a descriminalização do aborto, o casamento homossexual, a adoção por casais gays $e$ declarou "intolerante" o veto à ostentação de símbolos religiosos em repartições públicas. Diante disso, Lula propôs sua revisão, mantendo a defesa do aborto como questão de saúde pública, mas suprimindo trecho da autonomia das mulheres sobre seus corpos. Em 2010, após a CNBB recomendar o voto "em pessoas comprometidas com o respeito incondicional à vida", Lula assegurou que modificaria o Plano, embora bispos reforçassem a campanha contra a governista. Dilma comprometeu-se em não promover a descriminalização do aborto nem a criminalização da homofobia pelo Projeto de Lei 122/2006. As lideranças religiosas, portanto, obtiveram êxito em transformar a "defesa da vida", a moral sexual e familiar cristã tradicional numa arma, dificultando a secularização das campanhas, o debate político e a ordem jurídico-política dos direitos de mulheres e homossexuais.

Pesquisa Datafolha, de 26 de outubro de 2010, revelou que $36 \%$ do eleitorado considerava "muito importante" que a/o candidata/o fosse religiosa/o, enquanto $15 \%$ "um pouco importante" e 47\% "nada importante". Numa eleição decidida em dois turnos, a opinião de $36 \%$ das/os eleitoras/es que acham importante que a/o candidata/o seja religiosa/o pode ser decisiva em uma disputa apertada, especialmente quando Dilma era reconhecida como não religiosa. Ressalta-se que pesquisas Datafolha de 26 - 29 nov 2007 e de 26 nov 2010 revelaram que, no período em questão, aumentou de $31 \%$ para $36 \%$ a proporção 
de eleitoras/es que julgavam "muito importante" que a/o candidata/o fosse religiosa/o. Por isso, Mariano (2011:04) afirma que "o peso da religião e de questões de natureza moral $e$ religiosa sobre a esfera pública brasileira revelou-se de forma contundente na última eleição presidencial".

A radical oposição cristã fez estragos eleitorais na candidatura petista e os estrategistas da campanha demoraram a percebê-los. Pesquisas do IBOPE revelaram que, entre 26 de agosto e 23 de setembro, a intenção de voto das/os evangélicas/os na candidata havia caído de $49 \%$ para $42 \%$, oito pontos abaixo de sua média no conjunto do eleitorado, e sua rejeição havia saltado de $17 \%$ para $28 \%$ nesse segmento religioso. Os pontos perdidos entre as/os evangélicas/os e católicas/os, conforme institutos de pesquisa, colaboraram para levar a eleição para o segundo turno. Para enfrentar a nova etapa, a campanha governista reforçou o ativismo favorável de lideranças religiosas. Portanto, naquele momento, o posicionamento sobre a questão do aborto se revelou não apenas como um campo de disputas políticas, mas como uma "arena de luta política" (Rosado-Nunes, 2009).

Em decorrência da aflição entre os dirigentes petistas no fim do primeiro turno, o secretário de comunicação do partido, André Vargas, declarou ter sido um erro pautar-se internamente por feministas, revisando a posição a respeito da descriminalização do aborto. Na segunda semana de outubro, reunidos com a coordenação da campanha, representantes evangélicos aproveitaram a situação de fragilidade da candidata no plano religioso para lhe cobrar novamente o compromisso de assegurar a liberdade religiosa, vetar qualquer projeto aprovado pelo Congresso contra a vida, os valores da família, pró-casamento homossexual e adoção por esses casais, bem como projeto criminalizador da homofobia e pró-regulamentação das profissionais do sexo. Esse foi o momento em que as lideranças dispuseram do maior influência sobre a petista.

É importante se perguntar, por um lado, sobre que tipo de religião há dentro da cultura política atual, uma vez que as/os 
agentes religiosas/os se articulam em uma gramática orquestradora da sociedade; por outro, como o elemento religioso impregna seu ethos na ação política do país. As igrejas mencionadas, independente dos seus aspectos espirituais, atuam como organizações e constituem-se em corporações, disseminando uma visão de mundo e projetos doutrinais uniformizadores por parte das/os dirigentes.

Segato (2002 e 2007) aponta para a produção de uma nova ordem territorial a partir da religiosidade contemporânea e dos processos de globalização, desenhados concomitantemente à deteriorização dos Estados Nacionais. Se o território era um espaço fixo, marcado por um grupo que nele inscrevia suas características identitárias, a experiência histórica e culturalmente definida do território tem sido vivenciada por grupos que se comportam como pátrias secundárias, em suas formas de organização, coesão interna e apropriação espacial. Seus membros têm levado os marcadores territoriais em si mesmos e expandem seu território à medida que aumentam as adesões. Hoje, um grupo se refere a portadoras/es de padrões de lealdade comum, que institui um território no espaço por onde seus membros circulam e imprimem uma paisagem emanada de uma bagagem mental e de um estilo comportamental, dentro de padrões próprios de administração. Trata-se de "identidades políticas", as quais se referem a um horizonte global de modelos de identificação, a uma galeria transnacional de identidades de referências instrumentais na formulação de demandas por direitos e recursos.

A religiosidade se reduz ao papel de repertório de emblemas voltados a essa nova modalidade de territorialização: a religião se torna superficial em conteúdos doutrinários e na profundidade da discussão teológica para dar lugar à ênfase em fórmulas litúrgicas, disciplinares e ornamentais como emblemas claros de pertencimento político, que são logomarcas. É essencial para seu sentido de grupo investir em ícones (símbolos reduzidos, de baixa densidade, demarcadores de uma unidade chamada de política). Os ícones diacríticos, que os sujeitos 
portam, constituem o sujeito coletivo numa paisagem desvinculada do espaço físico determinado.

O Estado e a República são cada vez mais inexpressivos, passam a ser percebidos como espaços passíveis desse fracionamento entre coletivos políticos de base religiosa, internamente hierarquizados, divisores do capital simbólico $e$ material do que antes era "o público". Este, especialmente em países latinos, caracterizados por classes dominantes subalternas às elites do dito primeiro mundo, adquire o aspecto de um espaço transitável por uma variedade de instituições estatais e não estatais, sem monopólio da administração e controle por parte do Estado. Surgem aí grupos corporativos que se apropriam de cotas desse espaço simbólico e material, revelando, assim, a República como espaço deserto e desatendido, exposto a novas expressões de colonização e à anexação por legiões corporativas agressivas, que avançam sobre ela e articulam, em algumas ocasiões, alianças para sua partição.

$\mathrm{Na}$ América Latina, por exemplo, o Vaticano coloca-se como ator central e se faz presente interferindo para além do âmbito da Igreja em um processo de retorno a valores tradicionais em meio a uma intensa transformação cultural desde os anos 1960, acentuada nos últimos 15 anos com a eleição de governantes de esquerda. Segundo Arilha (2012), o Vaticano vem atuando, portanto, com uma política de formação de recursos humanos qualificados e estrategicamente situados na definição de leis, na criação de barreiras a medicamentos e no controle de candidatos/as comprometidos/as com o avanço dos direitos sexuais e reprodutivos. Afinal, trata-se de um continente aglutinador de um número significativo de católicos/as. O tipo de relação que essas redes coorporativas, também religiosas, mantêm com os Estados é dupla. Por um lado, em sua nova forma de soberania e fidelidades grupais, atravessam os antigos territórios pátrios e interatuam com mais de um Estado, negociando seu status de existência dentro de sua jurisdição e pressionando por reconhecimento. Por outro, sua capacidade de apropriarem-se de 
O aborto e o uso do corpo feminino na política

porções de influência em um ou mais campos da vida é consequência de sua existência. $\mathrm{O}$ impacto dessa configuração na política é grande, já que, em regimes democráticos, a consistência e coesão do grupo o identificam com uma massa de votantes, que elege um/a candidato/a e se esforça para converter o próprio Estado e suas instituições em território regulado e marcado com os emblemas de sua apropriação.

A política de identidade é simbólica e, também, material: o novo fiel - e todos os recursos a ele associados, dentre os quais, sua capacidade eleitoral expressada no voto - é um elemento que a rede incorpora. Trata-se da conquista de um território indissociavelmente espiritual e concreto. O primeiro impacto dessa nova territorialidade se nota na incursão das religiões na política e sua competição por participação no governo. As pessoas são pressionadas a alinhar-se em torno dos signos que demarcam essas jurisdições, sob o risco de não encontrarem meios para alcançar seus interesses. Esses grupos criam novas soberanias como verdadeiros "para-estados", com recursos próprios e formas de autodefesa, refazendo a tríade "soberania-controle-governo".

Diante desses argumentos, não é de se espantar a polêmica em torno da efetivação do III PNDH, exigindo de Lula sua revisão, assim como a posição do presidente da CNBB em 21 de outubro de 2010, quando defendeu que a questão do aborto deveria ser debatida na eleição presidencial e rejeitou a acusação de que a Igreja Católica estaria se intrometendo para além de sua competência ou querendo impor seus dogmas: "Estado laico não é sinônimo de Estado ateu ou antirreligioso" (Folha de São Paulo, 22/10/2010). Sua enunciação foi corroborada pelo papa Bento XVI, em 28 de outubro de 2010, às vésperas da finalização do segundo turno eleitoral.

As Igrejas também nutrem sua certeza de coesão ao ver os dividendos políticos de um voto consistente com seus projetos. $\mathrm{O}$ modelo corporativo não somente domina o exterior da Igreja, no campo da política, como também retorna a ela reforçando a corporação. Os grupos religiosos têm benefício interno por meio 
da pressão que exercem na sociedade secularizada. Em reciprocidade às investidas eleitorais da e do candidata/o para conquistar o apoio de católicas/os e evangélicas/os, as/os religiosas/os abrem-lhes espaço em seus eventos. Enfim, procuram obter prestígio e reconhecimento estatal para suas organizações, estreitar relações e ampliar sua influência na esfera pública, bem como ampliar suas/seus adeptas/os.

\title{
3. Religião e o controle do corpo feminino
}

O lema "nosso corpo nos pertence" continua sendo uma das principais bandeiras do movimento feminista desde a década de 1970, o qual reafirma a importância das reivindicações que, no Brasil e em outros países, levaram à reformulação do conceito de saúde, estabelecendo como prioridade o livre direito da mulher à contracepção (Giffin, 1991): as mulheres tendo direito de decidir sobre seu corpo, assim como se querem ou não ter filhas/os, em que momento, de que forma e com quem querem tê-las/os. Tratase de "direito reprodutivo", que está vinculado à efetivação de políticas públicas. Nessa direção concluiu Barsted (2009:228):

\begin{abstract}
Apesar dessas características adversas, tanto em 1992 como ainda hoje, considero que a demanda por autodeterminação [sobre o próprio corpo] e, em particular, por autodeterminação reprodutiva, incluindo o direito ao aborto, já na década de 1980 não representava uma ideia fora de lugar.
\end{abstract}

O referido lema veio, portanto, romper com uma dupla representação da mulher: a identificação dela com a natureza $e$ com sua condição de subordinação. Estas representações, naturalizadas no corpo da mulher, cuja função principal é tida como a de procriar, levam à desvalorização do feminino na sociedade patriarcal (Ortner, 1979).

O corpo feminino é visto por alguns segmentos cristãos como essencialmente destinado a servir à reprodução e, quando 
O aborto e o uso do corpo feminino na política

isso não ocorre, pode haver interferências tanto pelo Estado como por parte de religiosos/as na tentativa de regulamentação da sexualidade, do casamento, dentre outros. Giffin (1991:5) lembra

que não se deve confundir uma função biológica da atração
sexual, a reprodução da espécie, com a ideia da
reprodução como motivo individual e social para a
atividade sexual. Na atualidade, a reivindicação feminista
para o controle do corpo tem colocado claramente a
ideologia da dissociação entre sexualidade e reprodução,
estabelecendo prioridade para a contracepção e o aborto
legal como instrumentos de 'libertação' da mulher,
fundamentais na luta para uma maior igualdade - na
sexualidade e no exercício do trabalho remunerado.

É exatamente a dissociação entre as funções de procriação do corpo e o desejo sexual que ainda não se realizou nas relações sociais do senso comum, e é foco da interferência religiosa para mantê-los unidos e não permitir a autonomia das mulheres.

Nessa direção, a candidata e o candidata se viram pressionadas/os pelas igrejas e pelos segmentos conservadores do Congresso Nacional. Maria José Rosado Nunes ${ }^{1}$, liderança de uma ONG católica, opôs-se ao jogo das autoridades religiosas e criticou a posição de Dilma e Serra, que, segundo ela, deveriam se remeter ao Congresso. Este

seria o lugar certo, mais livre da coação de grupos religiosos ou fundamentalistas, o que aconteceria na hipótese de um plebiscito. O Congresso é o fórum possível para este debate, que é uma questão de saúde pública. (...) Liberdade de consciência é tradição cristã. O aborto é uma questão

\footnotetext{
1 Maria José Rosado Nunes coordena a ONG "Católicas pelo direito de decidir", que tem levado uma incansável batalha pela legalização do aborto. Em seu site www.catolicas.org.br publica a plataforma de lançamento da Frente Nacional contra a Criminalização das Mulheres e pela Legalização do Aborto, datada de setembro de 2010.
} 
social e política. Mas é uma decisão individual, de cada consciência de cada mulher. Nem Papa nem bispo nem pastor podem passar por cima da consciência individual.

Ela ainda expressa descontentamento ao acompanhar o tema na eleição: "não faz sentido, o único interesse é o de não perder votos, é o interesse político e partidário que prevalece sobre o interesse da nação" (Nunes, 2010:2).

Enfim, os corpos femininos ainda são vistos como objetos $e$ há quem se sirva deles como "moeda de troca". O aborto é problema de saúde pública e direito individual de cada mulher. Não se deveria partidarizar uma questão que não pertence a partido político, mas a uma política de estado, da saúde pública. Trata-se de um debate público sobre o aborto diretamente relacionado aos direitos sexuais e reprodutivos. Também não se deveria jogar para o campo religioso o que é de foro íntimo, por envolver, sobretudo, o corpo e a vida das mulheres.

Uma preocupação obsessiva crescente com o controle do corpo feminino e a oposição ao aborto, por parte de quem nada tem a ver com a vida particular ou a adesão religiosa individual, são partes desse fenômeno de publicização da fé.

Contracepción, relaciones sexuales pre-conyugales, recurso a preservativos para prevenir el SIDA, y numerosas práticas salen del fuero íntimo y del ámbito privado para ser ostensivamente proscriptas por razones que se ocultam por detrás de enunciados seudo-doctrinarios: para presentar al mundo una imagen de cohesión de red. La sanción sobre el cuerpo de la mujer es un lugar privilegiado para significar el dominio y la potencia cohesiva de la colectividad, y prácticas de larguíssima duración histórica confirman esta función de la capacidad normativa (y hasta predadora) sobre el cuerpo feminino como índice de la unión y la fuerza de una sociedad. La significación territorial de la corporalidad femenina - equivalencia y continuidad semántica entre cuerpo de mujer y territorio - son el fundamento cognitivo de estas práticas (Segato, 2007:322). 
O aborto e o uso do corpo feminino na política

A evocação do tradicionalismo, com seu automatismo, superficialidade e o reforço de uma moral coletiva rigorosamente apoiada em normas formais, cria e exibe uma modelagem unificada da conduta dos sujeitos, especialmente das mulheres. Essa unidade, que tem que ser visível para um grupo obter a coesão e a materialidade necessárias à sua existência, revela a pressão para que as mulheres exibam os signos da adesão. $\mathrm{O}$ costume e os aspectos externos da vida religiosa são cruciais nessa exacerbação do rigor sobre os signos diacríticos $e$ espetacularizáveis do pertencimento ao grupo. Este comando se soma à observação das Igrejas na forma de vestir e apresentar-se das mulheres. Uma vez que o grupo é o território, o corpo feminino e a geração de filhas/os se tornam uma anexação, uma continuidade dele, a ser conquistado e mantido sob vigilante controle em momentos de uniformização, como as eleições.

$\mathrm{O}$ alinhamento com uma rede religiosa e a exibição de sua marca corporal é o que se mostra como palanque na luta por recursos e direitos, cada vez mais a única proteção dos pobres $e$ vulneráveis na disputa generalizada, que cresce com 0 esvaziamento da República. Constata-se entre os setores carentes a coação estrutural à eleição $e$ ao consequente comportamento regimentado. A religião passa a comportar-se como uma entre outras identidades politizadas, num mundo de identidades fortemente uniformizadas, tanto que o tema central nessa lógica é menos a convicção que a representação, inclusive a representação de ser mulher, assentada em estereótipos baseados na maternidade sagrada. A elaboração dos conteúdos teológicos e da deliberação interna por parte de cada pessoa a respeito de seus costumes e valores é menos importante para a vitalidade da rede e a externalização da lealdade de seus membros. 


\section{A mulher presidenta: entre a pressão religiosa e as demandas feministas}

A novidade desse pleito eleitoral estava na apresentação de duas mulheres candidatas no primeiro turno: Marina Silva (Partido Verde - PV) e Dilma Rousseff. Na América Latina, são poucas as candidaturas femininas. ${ }^{2}$ É inegável que está havendo uma mudança de mentalidade, não apenas pela presença de mais candidatas, como pelo fato de que não há divulgação de que elas, no geral, estiveram envolvidas em escândalos e desvios de recursos públicos. Outro ponto é a chegada de uma mulher ao topo do poder executivo brasileiro, o que se associa à ideia de maior promoção da igualdade de gênero. Logo, com a ascensão de mulheres no poder, a expectativa é que seus direitos avancem. No entanto, a história recente não tem evidenciado isso, como diz Pimentel:

Elas abalam a ordem social tradicional, mas isso não significa que adotarão uma postura progressista. $\mathrm{Na}$ América Latina, as presidentes mantiveram o conservadorismo tanto em questões econômicas como em questões sociais - inclusive que afetam diretamente as mulheres, como a legalização do aborto. À exceção de Cuba, onde a interrupção voluntária da gravidez (IVG) é autorizada, e da Cidade do México, onde os deputados da Assembleia local a aprovaram, essa questão permanece um tabu na região (Oualalou, 2011:32).

Esse quadro paradoxal também se desenhou no Brasil, mediante a posição da petista na campanha eleitoral. Segundo

\footnotetext{
2 A segunda viúva de Juan Domingo Perón, Isabel Perón, esteve no poder entre 1973-74. Em outubro de 2011 Cristina Kirchner se tornou a primeira mulher reeleita para governar a Argentina. Em 2006, Michelle Bacelet, ex-refugiada política, foi eleita presidente do Chile. A Costa Rica driblou a tradicional cultura machista latina e elegeu Laura Chinchila. Em outubro de 2010, chegou a vez do Brasil com a eleição de Dilma Rousseff.
} 
O aborto e o uso do corpo feminino na política

Télia Negrão, coordenadora da Rede Feminista de Saúde em entrevista à RioSul TV em 21/12/2010,

todo mundo sabia que a candidata Dilma já tinha feito pronunciamentos favoráveis à legalização do aborto. (...) No processo eleitoral - essa posição partidária - se tornou uma moeda muito forte de barganha de acordos políticos $e$ a candidata Dilma acabou se submetendo (...) foi muito grave e acabou impactando as políticas que estão hoje no Ministério da Saúde (Negrão, 21/12/2010).

Arilha (2012) corrobora essa declaração, ao afirmar que, à época das eleições, o movimento feminista em geral não insistiu no debate público sobre os direitos reprodutivos, particularmente o aborto, em nome da vitória de Dilma, porém está pagando caro.

Nota-se que o impacto da eleição ainda é sentido em práticas políticas atuais, que ignoram o paradigma contemporâneo, defendido pelo movimento feminista e de mulheres, pelos setores democráticos e pela ciência. Tal paradigma se fundamenta na ideia de que a vida não começa na concepção, como insistem religiosas/os conservadoras/es. Para se constituir como sujeito, tem que haver vida extrauterina $e$, por isso, são apenas os direitos humanos das mulheres que importam para a legalização do aborto. Nesse sentido, a sociedade civil vem se mobilizando para superar o tradicionalismo da eleição.

Em dezembro de 2011 foi realizada a 3 $3^{\mathrm{a}}$. Conferência de Políticas para as Mulheres do Brasil, em Brasília, reunindo mais de 2500 delegadas e convidadas de 11 delegações internacionais. Feministas, trabalhadoras, sindicalistas, militantes diversas, acadêmicas, onguistas, entre outras, vindas de um processo que envolveu mais de 200 mil mulheres em todo o país. Reivindicaram, dentre vários temas, a única proposta que une o movimento feminista: "Contra a hipocrisia, pela legalização do aborto" (Lima e Pimentel, 2011). Presente na abertura da Conferência, a presidenta Dilma demonstrou seu compromisso 
com a manutenção da Secretaria de Política para às MulheresSPM, ligada à Presidência da República, ao se manifestar:

Nós vamos avançar com essa Secretaria, que defende o direito da mulher, que defende a igualdade de gênero. Essa Secretaria é fundamental, como é fundamental o movimento que cada uma de vocês faz nos municípios $e$ nas cidades de vocês.

$\mathrm{Na}$ ocasião, foi aprovado um conjunto de prioridades, decorrentes das reivindicações discutidas durante a. Conferência, que aponta para a consolidação de políticas públicas para as mulheres a serem executadas nos próximos três anos, de forma orquestrada entre União, Estados, Municípios, ONGs, instituições e movimento social. De certo modo, o lema "nosso corpo nos pertence" encontrase presente nessas prioridades, reafirmando a importância das questões de saúde dentro da pauta de reivindicações. Isso não significa que se deixe de valorizar a maternidade e a familia, mas deve se promover o respeito às opções individuais, especialmente em suas práticas sexuais e reprodutivas.

Uma das resoluções da Conferência foi justamente assegurar a autonomia das mulheres, para além da autonomia econômica, o que passa pela implantação de políticas públicas voltadas à esfera do corpo e dos cuidados. O eixo central foi "autonomia pessoal", com destaque para o tema da legalização do aborto, marcando o item "saúde integral das mulheres, sexualidade, direitos sexuais e direitos reprodutivos". A discussão teve como ponto forte a proposta das mulheres decidirem pela interrupção da gravidez, sem serem tratadas como criminosas e como prática assumida pelo Sistema Único de Saúde (SUS) (Vicente, 2011).

58. Revisão da legislação punitiva do aborto no Brasil, assegurando a descriminalização e legalização do aborto $e$ o atendimento humanizado na Rede de Saúde Pública do SUS, para que seja garantida a autonomia da mulher e que nenhuma mulher seja punida, maltratada ou humilhada por 
ter feito um aborto e não corra risco de morrer (Resoluções $3^{\text {a }}$ Conferência Nacional de Políticas para as Mulheres, 2011).

Vale lembrar que as concessões feitas pela candidata Dilma, não a comprometeram como Presidenta eleita a vetar a descriminalização do aborto, caso aprovado pelo Congresso Nacional. Por um lado, o recado aprovado pelas representantes das mulheres brasileiras na referida Conferência foi dado. Por outro lado, sabe-se que a articulação das/os conservadoras/es é eficiente e mobilizadora de massas. Então, cabe perguntar: a Presidenta Dilma conseguirá colocar em prática suas convicções e honrar seu apoio à maioria das mulheres brasileiras?

"Não será fácil recolocar o aborto na agenda política", afirma Télia Negrão, uma vez que a presidenta tem uma conjuntura desastrosa a enfrentar no decorrer dos próximos anos de seu mandato, pois estão no Congresso Nacional vários projetos contrários à legalização do aborto (Negrão, 2010). Em contraposição, há forte tendência a, pelo menos, ampliar os casos de aborto legal por parte da Comissão de Reforma do Código Penal do Senado, instalada em outubro de 2011, com o objetivo de elaborar o anteprojeto a ser analisado pelo Congresso. Em meio ao embate político entre segmentos religiosos $e$ as/os defensoras/es dos direitos das mulheres, ainda se mostram obscuros os passos futuros a serem dados pela Presidenta.

\section{Considerações Finais}

O tema do aborto foi ostensivamente usado como moeda na disputa política, voltado, sobretudo, contra a candidatura de uma mulher à presidência. Mariano (2011) infere que a forte campanha de oposição religiosa desencadeada contra Dilma e a tradicional resistência de parte do eleitorado pentecostal em relação ao PT levaram eleitoras/es a rejeitá-la. Nem mesmo a elevação de milhões de brasileiras/os à nova "Classe C", da qual provavelmente muitas/os pentecostais se beneficiaram, levou-as/os 
a optar pela petista, que era a preferida pela maioria desse grupo social. Dilma conseguiu reverter seu declínio nesse segmento religioso a partir do final do primeiro turno. Tendo $42 \%$ das intenções de voto dos/as evangélicos/as na pesquisa do Datafolha realizada em 23 de setembro de 2010, ela ganhou terreno nesse segmento religioso ao longo do segundo turno, chegando a $47 \%$ entre os pentecostais e $45 \%$ entre os protestantes em 30 de outubro de 2010. A estratégia de proteção da petista no segundo turno foi eficiente contra os boatos e a rejeição religiosa. Mas, não se pode desmerecer o poder político das igrejas, mesmo após a separação oficial Estado - Igreja, e que impregna a formação de uma cultura política de valores cristãos.

A estratégia da campanha de Serra, focada na conquista do eleitorado conservador, especialmente evangélico, e na desqualificação de sua adversária mostrou-se limitada. Sua candidatura sofreu danos decorrentes do "efeito fariseu" (Pierucci, 2011). Situação em que o candidato, ao abusar da personificação de uma imagem religiosa e de uma conduta moralista com fins eleitorais, se viu, à sua revelia, retratado como oportunista em uma farsa e aproveitador da influência da religião.

A última eleição presidencial marcou o retorno dos/as conservadores/as católicos/as à política nacional, após um longo período de atuação dos/as progressistas, protagonistas políticos do catolicismo nacional desde o fim da ditadura militar. Foi o grupo católico conservador, junto com dirigentes e políticos/as evangélicos/as, que pautaram a campanha presidencial. Dispostos/as a assegurar sua moralidade patriarcal para a sociedade e controlar frações da República, impuseram obstáculos à secularização do debate sobre a descriminalização do aborto e a criminalização da homofobia (Mariano, 2011).

Essa eleição, como nunca antes na história do país, teve uma acentuada instrumentalização entre política e religião, já que crenças $e$ moralidades religiosas foram empregadas tanto por autoridades religiosas como pelas campanhas. A e o principais candidata/os à presidência empenharam-se em buscar apoios, 
costurar alianças e, ao mesmo tempo, viram-se na contingência de ter de atender exigências de religiosas/os. Esse cenário aponta, de um lado, para a elevada influência religiosa em períodos eleitorais, e de outro, para a constituição da esfera pública atravessada pelas identidades religiosas contemporâneas e pela territorialização do corpo feminino como lócus legitimado de poder político, levando o Brasil a deixar de ser parâmetro de políticas públicas para a América Latina na "saúde das mulheres", como nos anos 1990.

As religiões em pauta nas eleições de 2010 são aquelas de superioridade moral, monopólicas e que pretendem controlar com exclusividade e com maniqueísmo as coletividades. A retórica dessas religiões se alimenta de um discurso de superioridade moral e afirma a coesão do grupo, precisamente, nos signos tradicionalistas, exibidos por seus membros e, em especial, no corpo das mulheres. Procuram intervir na atitude moral da coletividade para forçar transformações com uma finalidade preconcebida ou prescrever uma moral única para a humanidade, como condição para o acesso às vias do bem. São elas que dispõem de uma retórica que permite o alinhamento moral sob as consignas do grupo e aspiram a uma expansão predatória universal, fazendo das/os adeptas/os seu próprio território (Segato, 2007).

Contudo, cabe reafirmar que a recusa à despenalização do aborto no país, embora bastante mobilizada em termos religiosos, está assentada em um substrato mais amplo que aquele associado ao compromisso dos/as devotos/as com a determinação de suas lideranças cristãs. Evidentemente, em trabalhos futuros, é importante desenvolver a reflexão sobre a profundidade dos valores e das representações sociais relacionados a essa recusa, que acabam sendo mais efetivos no posicionamento político coletivo que exatamente nos comportamentos individuais. Haja vista que muitas mulheres se dizem contrárias à despenalização, mas apoiam pessoas conhecidas na prática do aborto ou elas mesmas já o realizaram, como mostra a pesquisa "Aborto no 
Brasil: uma pesquisa domiciliar com técnica de urna", realizada por Diniz e Medeiros (2010).

Além disso, outras pesquisas apontam para o fato de que o discurso contra o aborto e outros temas polêmicos relativos à vida humana na interface entre ciência e crenças, (células-tronco embrionárias, eutanásia, concepção, dentre outros) fundamenta-se em uma moral que define a vida (ou a dita "natureza") como um princípio transcendente. Esse é o discurso considerado legítimo no embate travado na esfera pública, em particular pelos referidos congressistas "pró-vida".

Cabe ainda ressaltar o fato do/a candidato/a terem se deixado, em alguma medida, se envolver pela problemática do aborto, uma vez que teriam argumentos suficientes em seus históricos pessoais e públicos, bem como elementos controversos e polêmicos na própria história das igrejas cristãs no Brasil, para se contraporem à estratégia de barganha delas. Por exemplo, como a opção dessas Igrejas pelos/as pobres pode ser coerente com a não despenalização do aborto em um país em que é essa parcela da população que mais sofre seus efeitos nocivos? Como não mencionar a política contrária aos métodos contraceptivos do Vaticano se as classes médias e altas fazem uso exatamente delas, o que desviaria o tema do aborto para práticas rotineiras $e$ disseminadas entre essa parcela de maior poder aquisitivo da população? Enfim, não o fizeram.

Compreender a complexa relação entre religião, política, direitos reprodutivos e sexualidade se volta hoje crucial. Se considerarmos que os campos religioso e político são capturados pela gramática da cultura ou ideologia de uma época, o processo histórico do político se remodela e encontra seu correlato na maneira em que os símbolos de identidade se ajustam a essa transformação. Tais símbolos reforçam a ideia do corpo feminino como mero objeto, como mercadorias religiosas, resultado da redução do símbolo a fetiche, a logomarcas. Por outro lado, a diminuição do poder exercido pela esfera estatal modifica a percepção e o funcionamento da República, passando a lidar com 
O aborto e o uso do corpo feminino na política

a competição acirrada por outras instituições em seu meio, que está reduzido a um mundo globalizado com baixa auto reflexividade e valores sexistas.

Por fim, cabe destacar que a manutenção da condenação do aborto pelas Igrejas, sob quaisquer circunstâncias, possibilita um enorme campo de transgressão para as mulheres, mas também de culpabilização e de impossibilidade de pensar o recurso a esse procedimento sob outro registro, que não o do julgamento religioso. É nesse sentido que o binômio "abortoreligião" oferece um campo provocativo de reflexão sobre as chances de se repensarem questões como a objetividade $e$ as relações sujeito-objeto nas pesquisas a seu respeito. Dada à inserção desse tema em um campo polêmico de decisões individuais, da autodeterminação da mulher e de investimento estatal, sobre o qual se fazem e refazem julgamentos de ordem moral, não há como não reconhecer a "contaminação" do temaobjeto (Barsted, 2009) em geral e, em particular, neste artigo.

\section{Referências bibliográficas}

ARILHA, Margareth Martha. Aborto: avanços na América Latina e retrocessos no Brasil? Le Monde Diplomatique Brasil, Fevereiro 2012, pp.10-11.

BARSTED, Leila Linhares. O Movimento das mulheres e o debate sobre o aborto. In: ROCHA, Maria Isabel Baltar e BARBOSA, Regina Maria (orgs). Aborto no Brasil e países do Cone Sul: panorama da situação $e$ dos estudos acadêmicos. Campinas, SP, Núcleo de Estudos de População - Nepo / Unicamp, 2009, pp.228 a 256.

CALADO, Maria Amélia G. A laicidade estatal face à presença de símbolos religiosos em órgãos públicos. Jus Navigandi, Teresina, ano $15, \mathrm{n}^{\circ}$ 2565, 10 jul. 2010. Disponível em: <http://jus.com.br/revista/texto/16962>. Acesso em: $1^{\circ}$ fev 2012.

Senado Federal. Constituição Federal - República Federativa do Brasil, Brasília, 1988. 
DINIZ, Débora e MEDEIROS, Marcelo. Aborto no Brasil: uma pesquisa domiciliar com técnica de urna. Ciência \& Saúde Coletiva, 15 (Supl. 1), Rio de Janeiro, 2010, pp.959-966.

DuARTE, Luiz Fernando Dias; HeIlborn, Maria Luiza; BARROS, Miriam Lins; PeIXOTO, Clarice (Orgs.). Família e Religião. Rio de Janeiro, Contracapa, 2006.

DuARTE, Luiz Fernando Dias; NATIVIDADE, M.; Gomes, E. C.; MENEZES, R. A. (Orgs.). Valores Religiosos e Legislação no Brasil: a tramitação de projetos de lei sobre temas morais controversos. Rio de Janeiro, Editora Garamond, 2009.

GIFFIN, Karen Mary. Nosso corpo nos pertence: a dialética do biológico e do social. Cadernos de Saúde Pública vol.7, n . 2, Rio de Janeiro, Apr./June, 1991, pp.190 a 200.

LimA, Luciana e PIMENTEL, Carolina. Dilma diz que Secretaria de Política para as Mulheres será mantida. Agência Brasil, em Brasília. UOLNoticias políticas, 12/12/2011. Disponível em: $<$ http://noticias.uol.com.br/politica/2011/12/12/dilma-diz-quesecretaria-de-politica-para-as-mulheres-sera-mantida.jhtm $>$.

MARIANO, Ricardo. Religião e política nas eleições presidenciais de 2010. Paper apresentado no XV Congresso Brasileiro de Sociologia - GT 19: Religião e Modernidade, julho de 2011, Curitiba (PR).

MASTRElla, Miryam. Os serviços de aborto legal na região Centro-Oeste. Projeto de Doutorado em Sociologia. Depto. De Sociologia, Universidade de Brasília, Brasília, 2011(mimeo).

MINISTÉRIO DA SAÚDE - MS/Área Técnica da Saúde da Mulher. Rio de Janeiro, 2007. Disponível em: $<\underline{\text { http://www.ccr.org.br/uploads/eventos/mag_aborto.pdf }>>}$

MUJICA, Jaris. Economia política del cuerpo: la reestructuración de los grupos conservadores y el biopoder. Centro de Promoción y Defensa de los Derechos Sexuales y Reproductivos, Lima, 2007.

NEGRÃO, Télia. Entrevista à RioSul TV, POA/RS, em 21/12/11. Disponível em: <http://sul21.com.br/jornal/2011/12/nao-vai-ser-facilrecolocar-aborto-na-agenda-politica-diz-telia-negrao/>. 
O aborto e o uso do corpo feminino na política

NUNES, Maria José. O aborto e as eleições presidenciais, entrevista a Celso Marcondes. Carta Capital, 05/10/2010. Disponível em: $<$ www.catolicas.org.br/artigos $>$ e <http://www.cartacapital.com.br/ politica/o-aborto-e-as-eleicoes-presidenciais $>$.

ORTNER, Sherry. Está a mulher para o homem como a natureza para a cultura? In: ROSALDO, Michelle e LAMPHERE, Louise (orgs). A Mulher, a Cultura e a Sociedade. Paz e Terra, SP, 1979.

OuAlalou, Lamia. O que mudou para as mulheres. Le Monde Diplomatique Brazil, ano 5, n 53, São Paulo, 2011.

PEREIRA, Victor Mauricio Fiorito. O Estado laico e a democracia, 2001. Disponível em: $<$ http://www.conamp.org.br/Lists/artigos/DispForm.aspx?ID=176>. Acesso em: $1^{\circ}$ fev 2012.

PIERUCCI, Antônio Flávio. Eleições 2010: desmoralização eleitoral do moralismo religioso. Novos Estudos, no 89, São Paulo, CEBRAP, março 2011, pp.05-15.

SEGATO, Rita Laura. Identidades políticas y alteridades históricas. Una crítica a las certezas del pluralismo global. Nueva Sociedad $n^{\circ} 178$ "Transnacionalismo y Transnacionalización", Buenos Aires, marzoabril, 2002, pp.104-125.

. La faccionalización de la República y el paisaje religioso como índice de una nueva territorialidad. In: SEGATO, Rita Laura. La nacion y sus otros: raza, etnicidad religiosa en tiempos de políticas de la identidad. Buenos Aires, Prometeo Libros, 2007, pp.309-350.

SeCRETARIA DE POLíticAs PARA MULHERES. Resoluções da $3^{a}$ Conferência Nacional de Políticas para as Mulheres, em 2011. Disponível em: $<$ http://www.sepm.gov.br/destaques/documentos/resolucoes-da3a-cnpm>.

Partido dos Trabalhadores. Resoluções do $3^{\circ}$ Congresso do PT em $2007 . \quad$ Disponível em: $<$ www.pt.org.br/arquivos/Resolucoesdo3oCongressodoPT.pdf $>$. 
Rede Feminista de SAÚdE. Rede Nacional Feminista de Saúde Direitos Sexuais e Reprodutivos. Saúde nas Eleições de 2010. Porto Alegre, RS, julho, 2010.

ROCHA, Maria Isabel Baltar e BARBOSA, Regina Maria (orgs). Aborto no Brasil e países do Cone Sul: panorama da situação e dos estudos acadêmicos. Campinas, SP, Núcleo de Estudos de População Nepo/Unicamp, 2009.

ROSALDO-NUNES, Maria José. Aborto e religião: as pesquisas no Brasil. In: ROCHA, Maria Isabel Baltar e BARBOSA, Regina Maria (orgs). Aborto no Brasil e países do Cone Sul: panorama da situação e dos estudos acadêmicos. Campinas, SP, Núcleo de Estudos de População - Nepo / Unicamp, 2009.

VÉLEZ, Ana Cristina González. Una mirada analítica a la legislación sobre interrupción del embarazo en países de Iberoamérica y el Caribe, CEPAL - Serie Mujer y desarollo no $110,2011$.

VICENTE, Terezinha. $3^{a}$ Conferência Nacional de Políticas para Mulheres aconteceu, viu, não viu? Disponível em: $<$ http://www.trezentos.blog.br/?p=6594> e $<$ http://www.spm.gov.br/>. 